\title{
1,3,5-Tris(functionalised-phenylethynyl)benzene-metal complexes: synthetic survey of mesoporous coordination polymers and investigation of their carbonisation
}

\author{
Norifumi Kobayashi and Masashi Kijima*
}

\author{
Receipt/Acceptance Data \\ Publication data \\ DOI: $10.1039 / b 000000 x$
}

\begin{abstract}
A series of multicoordinate 1,3,5-tris(functionalised-phenylethynyl)benzenes (1-9) was synthesised, and coordination polymers were constructed from these organic linkers and copper 10 ions in high yields. The carbonisation of the linkers 1-9 afforded a microporous carbon that shows type I adsorption-desorption isotherm. Although most of the coordination polymers prepared in this study turned out to be low porous materials, the coordination polymer 7e prepared from the reaction of 1,3,5-tris(4-carboxyphenylethynyl)benzene tripotassium salt $\left(\mathrm{K}_{3} 7\right)$ and copper (II) nitrate was a microporous material in addition to the mesoporous materials (7c and 7d) prepared 15 from the reaction of $\mathrm{K}_{3} 7$ with copper (II) acetate and copper (II) chloride, respectively. The carbonisation of the coordination polymers unexceptionally brought about an increase of micropore volume. A stepwise analysis of 7c pyrolysed at $350{ }^{\circ} \mathrm{C}, 600{ }^{\circ} \mathrm{C}$, and $900{ }^{\circ} \mathrm{C}$ revealed that the mesoporosity hardly changed upon heat-treatment, which demonstrates, in other words, that microporosity could be successfully added to the mesoporous coordination polymer through 20 the carbonisation process.
\end{abstract}

\section{Introduction}

Porous materials ${ }^{1}$ are generally classified into three groups, that is, carbon materials, ${ }^{2}$ inorganic materials, ${ }^{3}$ and coordination polymers. ${ }^{4}$ In particular, porous carbon materials 25 have uniquely electrical conductivity in addition to thermal, hydrothermal, and mechanical stabilities compared to those uncarbonised, and they are used for a wide variety of application purposes not only in hydrogen fuel storage, ${ }^{5}$ gas separation, ${ }^{6}$ water purification, ${ }^{7}$ catalysis or catalyst supports, ${ }^{8}$ 30 but also in energy storage devices such as lithium ion secondary battery ${ }^{9}$ and electric double layer capacitor. ${ }^{10}$

A surface activation procedure of the carbon or carbon precursor has conventionally been used to produce activated carbons, ${ }^{11}$ but it is hard to eliminate their inherancy of 35 inhomogeneous pore distribution. On the contrary to the activation method, the template synthesis is a promising method for constructing ordered nano-porous carbon materials. ${ }^{12}$ In this case, the specific space of porous inorganic materials such as zeolite has been utilised in porous carbon 40 synthesis, but inevitably the process is a reverse transcription of the template structure, and the template must be removed by post-cleaning using hydrofluoric acid or alkaline. After all, the pore structure of carbon is dependent on the template, and the mass production is difficult for the reason of the strict ${ }_{45}$ synthetic and removal processes.

On the other hand, the porous metal-organic frameworks

Institute of Materials Science, Graduate School of Pure and Applied Sciences, University of Tsukuba, Tsukuba, Ibaraki 305-8573, Japan. Fax: +8129853 4490; Tel: +8129853 6905; E-mail:

kijima@ims.tsukuba.ac.jp

$\dagger$ Electronic Supplementary Information (ESI) available: Syntheses, preparations, NMR spectra, thermogravimetric analysis plots, and $\mathrm{N}_{2}$ adsorption isotherms. See http://dx.doi.org/10.1039/b000000x/
(MOFs) also attract a profound research interest because of their shape-selective, predictable, topological architectures together with their homogeneous metal dispersion. ${ }^{13}$ It is 50 attractive to introduce these features to the porous carbon materials.

To our knowledge, despite many reports on synthesis of microporous MOFs (microMOFs) has been made, ${ }^{13 \mathrm{e}, 14}$ mesoMOF with permanent porosity exhibiting type IV ${ }_{55}$ adsorption-desorption isotherm has been reported only once. ${ }^{15}$ Hence, the synthesis of novel mesoMOFs and transformation from the MOFs to porous carbon are a great challenge in the field of chemistry of coordination polymers and carbon materials.

60 We have recently reported that the pyrolytic carbonisation of conjugated polymers having an alternative structure of the phenylene and carbon-carbon triple bond portions could afford microporous carbons in high yields above $80 \%$ under an argon flow. ${ }^{16}$ More recent reports have successfully 65 demonstrated that rigid networks of poly(aryleneethynylene) can construct microporous materials. ${ }^{17}$ It is also reported that large molecules having sixfold phenyleneethynylene bonds such as hexakis(4-functionalised-phenylethynyl)benzenes ${ }^{18}$ or hexakis[4-(4'-functionalised-henylethynyl)phenyl]benzenes ${ }^{19}$ 70 could serve as guest-inclusion organic crystals directed to organic zeolites because their rigid and starburst like structures tend to prevent network interpenetration.

For the reasons stated above, it is thought that multicoordinate $\pi$-conjugated molecules are appropriate as a 75 scaffold to construct novel mesoMOFs which can be carbonised with retaining the framework in consequence of their rigid structures and the higher carbon content than the general MOFs. In this study, we initially investigate what kind of $\pi$-conjugated organic linker that would be appropriate as a 
80 pre-carbon material to construct the carbonised MOFs. Next we synthesised some multicoordinate linkers, 1,3,5tris(functionalised-phenylethynyl)benzene derivatives, and their coordination polymers with copper salts. Last they were pyrolysed to investigate behaviors of the transformation from 85 coordination polymers to porous carbonised materials.

\section{Experimental}

\section{General method and instrumentations}

Synthetic manipulations shown in Scheme 1 were performed 90 under an argon atmosphere using a Schlenk glassware. The disk-pellet sample ( $\phi=13 \mathrm{~mm}, c a .50 \mathrm{mg})$ was prepared under a pressure of $3 \mathrm{MPa}$ using a press unit (Hitachi). The pellet sample on a quartz boat was carbonised in a quartz tube by heating up from room temperature to $900{ }^{\circ} \mathrm{C}$ at a rate of ${ }_{95} 5{ }^{\circ} \mathrm{C}$ min $^{-1}$ under flowing argon with a furnace EKRO-12K (Isuzu), then allowed to cool to room temperature and stored in a desiccator.

IR and NMR spectra were recorded on a JASCO FT/IR 550 spectrophotometer and a JEOL FT-NMR (270 MHz) 100 spectrometer, respectively. Elemental analyses were carried out with a Perkin-Elmer type 2400. Inductively coupled plasma (ICP) atomic emission spectroscopy were done on an ICAP 757 (Jarrell-Ash) plasma spectrometer. Thermal analyses were carried out by an Extra 6000 TG/DTA (Seiko) 105 thermogravimetric analyser at a rate of $10{ }^{\circ} \mathrm{C} \mathrm{min}{ }^{-1}$ except for hexakis(phenylethynyl)benzene (from $210{ }^{\circ} \mathrm{C}$ to $370{ }^{\circ} \mathrm{C}, 2^{\circ} \mathrm{C}$ $\mathrm{min}^{-1}$ ) under an argon atmosphere. X-ray diffraction (XRD) patterns were performed with a Rint 2100 (Rigaku) with a $\mathrm{Cu}$ $\mathrm{K}_{\alpha}(1.6418 \AA)$ radiation. Scanning electron microscopy 110 (SEM) images were acquired with a JSM-5610 (JEOL).

BET surface area was estimated from the results of $\mathrm{N}_{2}$ adsorption isotherm at $77 \mathrm{~K}$ measured with a SA 3100 (Coulter). The pore characterisations were also carried out by the $\alpha_{\mathrm{s}}$-plots for micropores and the DH method for mesopores, 115 respectively. ${ }^{19}$ The subtracting pore effect (SPE) analysis of the $\alpha_{\mathrm{s}}$-plots provides the total surface area $\left(A_{\text {total }}\right)$ from the slope of the narrow linear region around $\alpha_{\mathrm{s}}=0.5$, the external surface area $\left(A_{\text {ext }}\right)$ from the slope of the linear region between $\alpha_{\mathrm{s}}=0.7$ and 1.1, using the Eq. (1). The total micropore 120 volume $\left(V_{\text {micro }}\right)$ is also obtained from the intercept of the latter straight line. Further, the average micropore width $\left(w_{\alpha}\right)$ can be evaluated from the $A_{\text {total }}, A_{\text {ext }}$, and $V_{\text {micro }}$ according to the Eq. (2), assuming that the pore shape is slit-like.

$S_{\text {total }}=2.14 \times($ slope $)\left[\mathrm{m}^{2} \mathrm{~g}^{-1}\right]$

$125 w_{\alpha}=2 V_{\text {micro }} /\left(A_{\text {total }}-A_{\text {ext }}\right)[\mathrm{nm}]$

\section{Materials}

Triethylamine and THF were distilled after drying with $\mathrm{CaH}_{2}$ or sodium, respectively, under an argon atmosphere. The other solvents and reagents commercially available were used 130 without further Hexakis(phenylethynyl)benzene, ${ }^{21}$ purification. ${ }_{19}$ hexakis(4(tert-butyldimethylsilyloxy)iodobenzene ${ }^{23}$ were prepared according to the established procedure. 1,3,5-Tris(4135 cyanophenylethynyl)benzene (1) pyridylethynyl)benzene

(2), 25 $1,3,5$-tris $[4-$ (ethoxycarbonyl)phenylethynyl]benzene (6), 1,3,5-tris(4carboxyphenylethynyl)benzene $\left(\mathrm{H}_{3} 7\right)^{26}$ have been known in the literatures.

\section{${ }_{140}$ Synthesis}

1,3,5-Tris(5-pyrimidinylethynyl)benzene (3). To a mixture of CuI $(49.5 \mathrm{mg}, 0.260 \mathrm{mmol}), \mathrm{Pd}\left(\mathrm{PPh}_{3}\right)_{4}(300 \mathrm{mg}$, $0.260 \mathrm{mmol}), 1,3,5$-trietynylbenzene $(1.30 \mathrm{~g}, 8.66 \mathrm{mmol}), 5$ bromopyrimidine $(6.19 \mathrm{~g}, 39.0 \mathrm{mmol})$ were added $\mathrm{Et}_{3} \mathrm{~N}(15$

$145 \mathrm{~mL})$ and THF $(70 \mathrm{~mL})$, and the mixture was stirred at $55{ }^{\circ} \mathrm{C}$ for $12 \mathrm{~h}$ and then $70{ }^{\circ} \mathrm{C}$ for $14 \mathrm{~h}$. The reaction mixture was concentrated and extracted with $\mathrm{CHCl}_{3}$. The organic layer was washed with $\mathrm{H}_{2} \mathrm{O}$ and brine, and dried over $\mathrm{Na}_{2} \mathrm{SO}_{4}$. Reprecipitation from $\mathrm{CHCl}_{3}$-EtOAc-hexane gave 3 (3.13 g, $15094.0 \%$ yield) as a white solid. ${ }^{1} \mathrm{H}-\mathrm{NMR}\left(\mathrm{CDCl}_{3}\right) \delta 9.17(\mathrm{~s}$, $3 \mathrm{H}), 8.86(\mathrm{~s}, 6 \mathrm{H}), 7.75 \mathrm{ppm}(\mathrm{s}, 3 \mathrm{H}) ;{ }^{13} \mathrm{C}-\mathrm{NMR}\left(\mathrm{CDCl}_{3}\right)$ $\delta 158.6,157.1,135.0,123.1,119.1,93.7,84.2 \mathrm{ppm}$; IR $(\mathrm{KBr})$ $v 3033(\mathrm{~m}), 2220(\mathrm{w}), 1542(\mathrm{~s}), 1426(\mathrm{~s}), 1406(\mathrm{~s}), 877(\mathrm{~m})$, 631(m) $\mathrm{cm}^{-1}$; Anal. Calcd for $\mathrm{C}_{24} \mathrm{H}_{12} \mathrm{~N}_{6} \cdot 0.2$ EtOAc: C, 74.09; ${ }_{155} \mathrm{H}, 3.41$; N, 20.90. Found: C, 74.01; H, 3.59; N, 20.74.

\section{1,3,5-Tris[4-(tert-}

butyldimethylsilyloxy)phenylethynyl]benzene (4). A mixture of $\mathrm{CuI}(23.8 \mathrm{mg}, 0.125 \mathrm{mmol}), \mathrm{Pd}\left(\mathrm{PPh}_{3}\right)_{4}(144 \mathrm{mg}$, $0.125 \mathrm{mmol}$ ), 1,3,5-trietynylbenzene (625 mg, $4.16 \mathrm{mmol}), 4-$ 160 (tert-butyldimethylsilyloxy)iodobenzene $(5.97 \mathrm{~g}, 18.8 \mathrm{mmol})$, and THF $(40 \mathrm{~mL})$ in $\mathrm{Et}_{3} \mathrm{~N}(10 \mathrm{~mL})$ was stirred at $45^{\circ} \mathrm{C}$ for 18 h. Hexane was added to the reaction mixture, and the separated solid was filtered out. The filtrate was subjected to column chromatography on silica gel eluted with hexane${ }_{165} \mathrm{CH}_{2} \mathrm{Cl}_{2}$ (4:1) to give $4(2.75 \mathrm{~g}, 85.9 \%$ yield $)$ as a light yellow solid. $1.89 \mathrm{~g}$ of the overloaded iodide was recovered. ${ }^{1} \mathrm{H}-\mathrm{NMR}$ $\left(\mathrm{CDCl}_{3}\right) \delta 7.58(\mathrm{~s}, 3 \mathrm{H}), 7.42(\mathrm{~d}, J=8.7 \mathrm{~Hz}, 6 \mathrm{H}), 6.83(\mathrm{~d}, J=$ $8.7 \mathrm{~Hz}, 6 \mathrm{H}), 1.00(\mathrm{~s}, 27 \mathrm{H}), 0.23 \mathrm{ppm}(\mathrm{s}, 18 \mathrm{H}) ;{ }^{13} \mathrm{C}-\mathrm{NMR}$ $\left(\mathrm{CDCl}_{3}\right) \delta 156.1,133.4,133.0,124.1,120.2,115.5,90.4,86.9$, 170 25.7, 18.3, -4.2 ppm; IR (KBr): v $2929(\mathrm{~m}), 2211(\mathrm{w}), 1604$ (m), 1579 (m), 1507 (s), 1256 (s), 912 (s), 837 (s), 781 (m), $680(\mathrm{w}) \mathrm{cm}^{-1}$; Anal. Calcd for $\mathrm{C}_{48} \mathrm{H}_{60} \mathrm{O}_{3} \mathrm{Si}_{3}: \mathrm{C}, 74.95 ; \mathrm{H}, 7.86$; N, 0.00. Found: C, 74.94; H, 7.55; N, 0.00 .

1,3,5-Tris(4-hydroxyphenylethynyl)benzene $\quad\left(\mathrm{H}_{3} 5\right)$. A 175 mixture of 4 (4.08 g, $5.30 \mathrm{mmol})$, THF $(25 \mathrm{~mL}), \mathrm{MeOH}(100$ $\mathrm{mL})$, and $\mathrm{KOH}(1.40 \mathrm{~g}, 21.2 \mathrm{mmol})$ in $\mathrm{H}_{2} \mathrm{O}(5 \mathrm{~mL})$ was stirred at room temperature for $12 \mathrm{~h}$. The reaction mixture was diluted with $\mathrm{H}_{2} \mathrm{O}$, and the organic solvents were evaporated. The aqueous residue was acidified with $0.5 \mathrm{M} \mathrm{HCl}$ and 180 extracted with EtOAc. The organic layer was washed with $\mathrm{H}_{2} \mathrm{O}$ and brine and dried over $\mathrm{Na}_{2} \mathrm{SO}_{4}$ to give 5 (2.26 g, 99.9\% yield) as a light yellow solid. ${ }^{1} \mathrm{H}-\mathrm{NMR}\left(\mathrm{DMSO}-d_{6}\right) \delta 10.05$ (s, $3 \mathrm{H}), 7.61(\mathrm{~s}, 3 \mathrm{H}), 7.46(\mathrm{~d}, J=8.6 \mathrm{~Hz}, 6 \mathrm{H}), 6.87 \mathrm{ppm}(\mathrm{d}, J=$ $8.6 \mathrm{~Hz}, 6 \mathrm{H}$ ); ${ }^{13} \mathrm{C}-\mathrm{NMR}$ (DMSO- $d_{6}$ ) $\delta 158.2,133.1,132.4$, 185 124.0, 115.7, 111.8, 91.4, 85.7 ppm; IR (KBr) $v 3336(\mathrm{~m})$, $2209(\mathrm{w}), 1606$ (m), 1578 (s), 1509 (s), 1262 (m), 1220 (m), $1170(\mathrm{~m}), 830$ (s), $680 \quad(\mathrm{w}) \mathrm{cm}^{-1}$; Anal. Calcd for $\mathrm{C}_{30} \mathrm{H}_{18} \mathrm{O}_{3} \cdot 0.2 \mathrm{H}_{2} \mathrm{O}: \mathrm{C}, 83.78 ; \mathrm{H}, 4.31 ; \mathrm{N}, 0.00$. Found: $\mathrm{C}$, $83.59 ; \mathrm{H}, 4.46 ; \mathrm{N}, 0.14$.

$190 \quad$ 1,3,5-Tris(4-hydroxyphenylethynyl)benzene

tripotassium salt $\left(\mathbf{K}_{3} \mathbf{5}\right)$. A mixture of $\mathrm{H}_{3} \mathbf{5}(206 \mathrm{mg}, 0.483$ mmol) and $\mathrm{CH}_{3} \mathrm{OK}(102 \mathrm{mg}, 1.45 \mathrm{mmol})$ in $\mathrm{MeOH} 8 \mathrm{~mL}$ was concentrated to give $\mathrm{K}_{3} \mathbf{5}$ (256 mg, $98.1 \%$ yield) as a yellowbrown solid. ${ }^{1} \mathrm{H}-\mathrm{NMR}$ (DMSO- $\left.d_{6}\right) \delta 7.11(\mathrm{~s}, 3 \mathrm{H}), 6.98(\mathrm{~d}, J=$ 
$1958.6 \mathrm{~Hz}, 6 \mathrm{H}), 6.06 \mathrm{ppm}(\mathrm{d}, J=8.6 \mathrm{~Hz}, 6 \mathrm{H}) ;{ }^{13} \mathrm{C}-\mathrm{NMR}(\mathrm{DMSO}-$ $\left.d_{6}\right) \delta 173.4,133.0,128.3,125.5,119.3,97.3,96.0,84.8 \mathrm{ppm}$; IR (KBr): v $3434(\mathrm{~s}), 2200(\mathrm{~m}), 1596(\mathrm{~m}), 1575(\mathrm{~s}), 1498(\mathrm{~s})$, $1296(\mathrm{~s}), 1167(\mathrm{~m}), 841$ (m) $\mathrm{cm}^{-1}$; Anal. Calcd for $\mathrm{C}_{30} \mathrm{H}_{15} \mathrm{O}_{3} \mathrm{~K}_{3} \cdot 6.5 \mathrm{H}_{2} \mathrm{O}: \mathrm{C}, 54.77 ; \mathrm{H}, 4.29 ; \mathrm{N}, 0.00$. Found: $\mathrm{C}$, $20055.04 ; \mathrm{H}, 4.33$; N, 0.02 .

\section{1,3,5-Tris(4-carboxyphenylethynyl)benzene}

tripotassium salt $\left(\mathbf{K}_{3} \mathbf{7}\right)$. A mixture of $\mathrm{H}_{3} 7(800 \mathrm{mg}, 1.57$ $\mathrm{mmol}$ ) and $\mathrm{CH}_{3} \mathrm{OK}(330 \mathrm{mg}, 4.70 \mathrm{mmol})$ in $\mathrm{MeOH} 120 \mathrm{~mL}$ was concentrated to give $\mathrm{K}_{3} 7$ (980 mg, $100 \%$ yield) as a white 205 solid. ${ }^{1} \mathrm{H}-\mathrm{NMR}\left(\mathrm{CD}_{3} \mathrm{OD}\right) \delta 7.96(\mathrm{~d}, J=8.1 \mathrm{~Hz}, 6 \mathrm{H}), 7.68(\mathrm{~s}$, $3 \mathrm{H}), 7.55 \mathrm{ppm}(\mathrm{d}, J=8.1 \mathrm{~Hz}, 6 \mathrm{H}) ;{ }^{13} \mathrm{C}-\mathrm{NMR}\left(\mathrm{CD}_{3} \mathrm{OD}\right)$ $\delta$ 174.1, 139.3, 134.8, 132.0, 130.2, 125.48, 125.46, 91.5, 89.3 ppm; IR (KBr): v 3372 (s), $2214(\mathrm{w}), 1603$ (s), 1584 (s), 1540 (s), 1385 (s), 1279 (w), 842 (w), 786 (m) $\mathrm{cm}^{-1}$; Anal. ${ }_{210}$ Calcd for $\mathrm{C}_{33} \mathrm{H}_{15} \mathrm{O}_{6} \mathrm{~K}_{3} \cdot 3.83 \mathrm{H}_{2} \mathrm{O}$ : C, 57.13; H, 3.29; N, 0.00 . Found: C, 57.19; H, 3.46; N, 0.31

1,3,5-Tris(4-bromophenylethynyl)benzene (8). A mixture of CuI (56.2 mg, $0.295 \mathrm{mmol}), \mathrm{Pd}\left(\mathrm{PPh}_{3}\right)_{4}(340 \mathrm{mg}$, $0.295 \mathrm{mmol}), 1,3,5$-trietynylbenzene (1.47 g, $9.82 \mathrm{mmol}), 1$ 215 bromo-4-iodobenzene $(25.0 \mathrm{~g}, 88.4 \mathrm{mmol})$, and THF $(75 \mathrm{~mL})$ in $\mathrm{Et}_{3} \mathrm{~N}(22 \mathrm{~mL})$ was stirred at room temperature for $40 \mathrm{~h}$. The reaction mixture was concentrated and extracted with $\mathrm{CH}_{2} \mathrm{Cl}_{2}$. The organic layer was washed with $\mathrm{H}_{2} \mathrm{O}$ and brine, and subjected to column chromatography on silica gel eluted with 220 hexane $-\mathrm{CH}_{2} \mathrm{Cl}_{2}(7: 1)$ to give $8(5.92 \mathrm{~g}, 98.1 \%$ yield $)$ as a white solid. $16.3 \mathrm{~g}$ of the overloaded iodide was recovered. ${ }^{1} \mathrm{H}-\mathrm{NMR}\left(\mathrm{CDCl}_{3}\right) \delta=7.63(\mathrm{~s}, 3 \mathrm{H}), 7.50(\mathrm{~d}, J=8.4 \mathrm{~Hz}, 6 \mathrm{H})$, $7.37 \mathrm{ppm}(\mathrm{d}, J=8.4 \mathrm{~Hz}, 6 \mathrm{H}) ;{ }^{13} \mathrm{C}-\mathrm{NMR}\left(\mathrm{CDCl}_{3}\right) \delta 134.0$, 133.0, 131.6, 123.7, 122.9, 121.5, 89.6, 88.7 ppm; IR (KBr) $v$ 2252955 (w), 2922 (w), 2857 (w), 2210 (w), 1589 (s), 1486 (s),

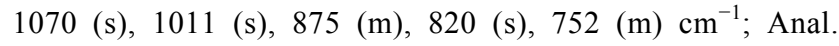
Calcd for $\mathrm{C}_{30} \mathrm{H}_{15} \mathrm{Br}_{3}$ : C, 58.57; H, 2.46; N, 0.00; Br, 38.97. Found: C, 58.27; H, 2.78; N, 0.00; Br, 38.24.

1,3,5-Tris[4-(dihydroxyboryl)phenylethynyl]benzene (9).

230 To a solution of $8(200 \mathrm{mg}, 0.325 \mathrm{mmol})$ in THF $(12 \mathrm{~mL})$ was added dropwise a hexane solution of $n$-BuLi $(2.60 \mathrm{M}, 750 \mu \mathrm{L}$, $1.95 \mathrm{mmol}$ ) at $-78{ }^{\circ} \mathrm{C}$. After stirring at $-78{ }^{\circ} \mathrm{C}$ for $1 \mathrm{~h}$ and then at $-20{ }^{\circ} \mathrm{C}$ for $1.5 \mathrm{~h}$, to the resulting solution was added $\mathrm{B}(\mathrm{OMe})_{3}(435 \mu \mathrm{L}, 3.90 \mathrm{mmol})$ at $-78{ }^{\circ} \mathrm{C}$. The resulting 235 mixture was warmed to room temperature for overnight with stirring, and then hydrolysed with $2 \mathrm{M} \mathrm{HCl}$ at $0{ }^{\circ} \mathrm{C}$. After evaporation of THF, the residue was extracted with EtOAc. The organic layer was washed with $2 \mathrm{M} \mathrm{HCl}, \mathrm{H}_{2} \mathrm{O}$, and brine, and dried over $\mathrm{Na}_{2} \mathrm{SO}_{4}$. After evaporation of EtOAc, the

240 residue was triturated with $\mathrm{CH}_{2} \mathrm{Cl}_{2}$ and filtered. The solid was recrystallised from benzene- $\mathrm{CHCl}_{3}-\mathrm{MeOH}$ to give $\mathbf{9}(125 \mathrm{mg}$, $75.5 \%$ yield) as a light yellow solid. ${ }^{1} \mathrm{H}-\mathrm{NMR}$ (DMSO- $d_{6}$ ) $\delta 8.20(\mathrm{~s}, 6 \mathrm{H}), 7.84(\mathrm{~d}, J=8.1 \mathrm{~Hz}, 6 \mathrm{H}), 7.76(\mathrm{~s}, 3 \mathrm{H}), 7.55$ ppm $(\mathrm{d}, J=8.1 \mathrm{~Hz}, 6 \mathrm{H}) ;{ }^{13} \mathrm{C}-\mathrm{NMR}$ (DMSO- $\left.d_{6}\right) \delta 135.2,134.2$, ${ }_{245} 133.7,130.3,123.6,123.0,91.1,88.1$ ppm; IR (KBr) $v 3400$ (s), 3075 (w), 2208 (w), 1604 (s), 1341 (s), 1016 (w), 834 (w), 749 (w) $\mathrm{cm}^{-1}$; Anal. Calcd for $\mathrm{C}_{30} \mathrm{H}_{21} \mathrm{~B}_{3} \mathrm{O}_{6}$ : C, 70.66; H, 4.15; N, 0.00. Found: C, 70.62; H, 4.45; N, 0.00 .

Preparation of $7 \mathrm{c}\left(\mathbf{7} \cdot \mathbf{C u} \cdot \mathbf{K} \cdot 2 \mathrm{CH}_{3} \mathrm{CO}_{2} \cdot \mathbf{M e O H}\right)$. To a 250 solution of $\mathrm{K}_{3} 7(120 \mathrm{mg}, 0.192 \mathrm{mmol})$ in $\mathrm{MeOH}(40 \mathrm{~mL})$ was added dropwise a solution of $\mathrm{Cu}\left(\mathrm{CH}_{3} \mathrm{COO}\right)_{2}(105 \mathrm{mg}, 0.576$ $\mathrm{mmol})$ in $\mathrm{MeOH}(25 \mathrm{~mL})$ at refluxing temperature for $2 \mathrm{~h}$ and then slowly cooled to room temperature. A blue precipitate was collected by filtration and evacuated at $80{ }^{\circ} \mathrm{C}$ for $12 \mathrm{~h}$ 255 (135 mg, 85.5\% yield). This compound was insoluble in common organic solvents such as DMAc and DMSO. IR $(\mathrm{KBr}) v 3389(\mathrm{~m}), 1695$ (w), 1604 (s), 1578 (s), 1533 (s), 1411 (s), 1177 (w), 1098 (w), 1016 (w), 860 (m), 779 (m) $\mathrm{cm}^{-1}$; Anal. Calcd for $\left(\mathrm{C}_{38} \mathrm{H}_{25} \mathrm{Cu}_{2} \mathrm{O}_{11} \mathrm{~K}\right)_{n}$ : C, 55.40; H, 3.06; N 260 0.00; $\mathrm{Cu}, 15.4$. Found: C,55.29; H, 3.25; N, 0.20; Cu, 16.3. Metal concentration analyses were performed by ICP analysis for all coordination polymers.

Preparation of $7 \mathbf{d}(\mathbf{7} \cdot 1.5 \mathrm{Cu} \cdot 0.25 \mathrm{KCl} \cdot 1.5 \mathrm{MeOH})$. To a solution of $\mathrm{K}_{3} 7(120 \mathrm{mg}, 0.192 \mathrm{mmol})$ in $\mathrm{MeOH}(40 \mathrm{~mL})$ was 265 added dropwise a solution of $\mathrm{CuCl}_{2} \cdot 2 \mathrm{H}_{2} \mathrm{O}(98.2 \mathrm{mg}, 0.576$ $\mathrm{mmol})$ in $\mathrm{MeOH}(5 \mathrm{~mL})$ at refluxing temperature for $2 \mathrm{~h}$ and then slowly cooled to room temperature. A blue precipitate was collected by filtration and evacuated at $80{ }^{\circ} \mathrm{C}$ for $12 \mathrm{~h}$ (114 mg, 88.6\% yield). This compound is insoluble in most of 270 solvents. IR (KBr) v $3045(\mathrm{~m}), 1695(\mathrm{~m}), 1604(\mathrm{~s}), 1580$ (s), 1535 (m), 1411 (s), $1281(\mathrm{w}), 1176(\mathrm{w}), 1099$ (w), 1017 (w), $859(\mathrm{w}), 779(\mathrm{~m}) \mathrm{cm}^{-1}$; Anal. Calcd for $\left(\mathrm{C}_{138} \mathrm{H}_{84} \mathrm{ClCu}_{6} \mathrm{O}_{30} \mathrm{~K}\right)_{n}$ : $\mathrm{C}, 61.89 ; \mathrm{H}, 3.16 ; \mathrm{N}, 0.00 ; \mathrm{Cl}, 1.32 ; \mathrm{Cu}, 14.24$. Found: $\mathrm{C}, 61.88 ; \mathrm{H}, 3.42 ; \mathrm{N}, 0.50 ; \mathrm{Cl}, 2.82 ; \mathrm{Cu}, 14.3$.

Preparation of 7 e $\left(\mathbf{7} \cdot \mathbf{1 . 5 C u} \cdot \mathbf{6} \mathrm{H}_{2} \mathrm{O}\right)$. A solution of $\mathrm{K}_{3} 7$ (70 $\mathrm{mg}, 0.112 \mathrm{mmol})$ in $\mathrm{DMF} / \mathrm{MeOH}(7: 1 \mathrm{v} / \mathrm{v}, 80 \mathrm{~mL})$ was placed in a long Pyrex tube with a $15 \mathrm{~mm}$ internal diameter. A solution of $\mathrm{Cu}\left(\mathrm{NO}_{3}\right)_{2} \cdot 3 \mathrm{H}_{2} \mathrm{O}(54.1 \mathrm{mg}, 0.224 \mathrm{mmol})$ in $\mathrm{DMF} / \mathrm{MeOH}(1: 1 \mathrm{v} / \mathrm{v}, 4 \mathrm{~mL})$ was carefully layered on the top 280 of the $\mathrm{K}_{3} 7$ solution, followed by layering $1 \mathrm{~mL}$ of the mixed solvent $\mathrm{DMF} / \mathrm{MeOH}(2: 1 \mathrm{v} / \mathrm{v})$ of intermediate density. The mixture was allowed to stand for 10 days at room temperature. The mixture was heated to a refluxing temperature for $5 \mathrm{~h}$ and then slowly cooled to room temperature. A blue precipitate 285 was collected by filtration and evacuated at $80{ }^{\circ} \mathrm{C}$ for $12 \mathrm{~h}$ (76.0 $\mathrm{mg}, 95.4 \%$ yield). This compound was insoluble in water and common organic solvents. IR (KBr) $v 3421$ (s), 1604 (s), 1581 (s), 1537 (m), 1409 (s), 1177 (w), 1099 (w), $1017(\mathrm{w}), 861(\mathrm{w}), 780(\mathrm{~m}) \mathrm{cm}^{-1}$; Anal. Calcd for ${ }_{290}\left(\mathrm{C}_{66} \mathrm{H}_{54} \mathrm{Cu}_{3} \mathrm{O}_{24}\right)_{n}: \mathrm{C}, 55.76 ; \mathrm{H}, 3.83 ; \mathrm{N}, 0.00 ; \mathrm{Cu}, 13.41$. Found: C,56.02; H, 3.84; N, 0.32; Cu, 14.9.

\section{Results and discussion}

Thermal Analysis of Organic Linkers 
295 To select a thermally stable organic linker, thermogravimetric analysis (TGA) and differential thermal analysis (DTA) of multicoordinate frameworks of hexakis(phenylethynyl)benzene, hexaphenylbenzene, and 1,3,5-tris(phenylethynyl)benzene were performed and the 300 results are shown in Figure 1. These compounds are highly symmetrical $\left(D_{6 \mathrm{~h}}\right.$ or $\left.D_{3 \mathrm{~h}}\right)$, which can support radial coordination-bonding sites to form a predictable network with cavity based on the multipoint cooperative interactions, and can make an orthogonal arrangement of the interactive

305 benzene-centered moieties in the network. ${ }^{27}$ Judging from their TGA and DTA traces, hexakis(phenylethynyl)benzene is not appropriate for an organic linker because the Bergmantype cyclisation ${ }^{28}$ occurs with an intensive exothermic peak at about $295^{\circ} \mathrm{C}$, although it showed the high carbonised residual 310 ratio at $900{ }^{\circ} \mathrm{C}(78 \%)$. Therefore, the multiple bonds of the molecule must have distance from each other to prevent the Bergman-type cyclisations in the pyrolytic process. In the case of the hexakis(4-cyanophenyl)benzene, the exothermic peak was scarcely observed, but it is also inadequate for an 315 organic linker because thermal cracking of the phenyl-phenyl bonds occurred at around $550{ }^{\circ} \mathrm{C}$, which was reflected in its relatively low carbonisation yield $\left(49 \%\right.$ at $\left.900{ }^{\circ} \mathrm{C}\right)$. From this standpoint, the star-shaped 1,3,5-tris(4cyanophenylethynyl)benzene could have an optimal structure.

320 As a consequence, it showed the mild pyrolysis process similar to hexakis(4-cyanophenyl)benzene in addition to the high carbonisation yield equivalent to hexakis(phenylethynyl)benzene.

\section{Synthesis of functionalised 1,3,5-tris(substituted-}

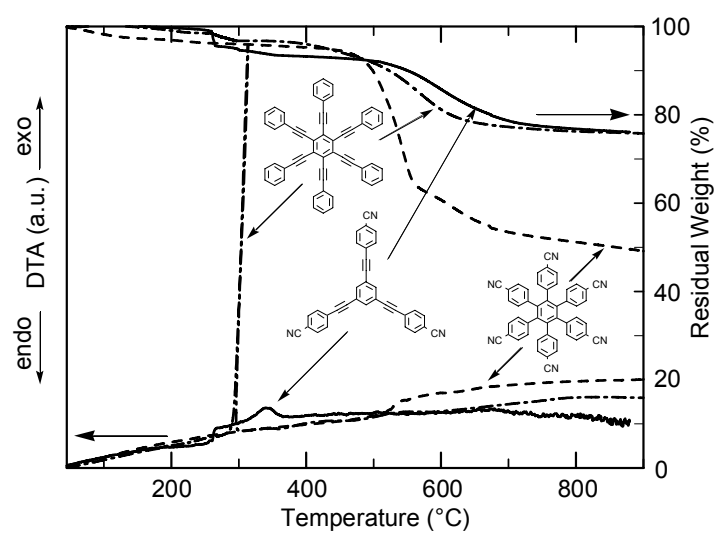

Fig. 1 TGA-DTA curves of hexakis(4-cyanophenyl)benzene, hexakis(phenylethynyl)benzene, and 1,3,5-tris(4cyanophenylethynyl)benzene.

\section{${ }_{325}$ phenylethynyl)benzenes}

Sonogashira coupling reaction is a powerful method for the synthesis of differentially functionalised 1,3,5tris(phenylethynyl)benzenes because the reaction is tolerant of functional groups such as cyano and pyridyl groups. ${ }^{29} 1,3,5$ -

330 Triethynylbenzene was synthesised in $96 \%$ total yield by the reactions of 1,3,5-tribromobenzene with trimethylsilylacetylene and following desilylation. The Sonogashira coupling reaction of 1,3,5-triethynylbenzene with a functionalised phenylhalide in $\mathrm{Et}_{3} \mathrm{~N}-\mathrm{THF}$ in the presence of
${ }_{335} \mathrm{Pd}\left(\mathrm{PPh}_{3}\right)_{4}$ and $\mathrm{CuI}$ was carried out to synthesise 1,3,5tris(substituted-phenylethynyl)benzenes (Scheme 1). 4Cyanophenyl (1), 4-pyridyl (2), 5-pyrimidinyl (3), 4-(tertbutyldimethylsilyloxy)phenyl (4), 4-(ethoxycarbonyl)phenyl (6), and 4-bromophenyl (8) groups were successfully 340 introduced to 1,3,5-triethynylbenzene in high yields. The deprotection of the silyl ether of $\mathbf{4}$ and the ethyl ester of $\mathbf{6}$ with $\mathrm{KOH}$ gave 1,3,5-tris(4-hydroxyphenylethynyl)benzene $\left(\mathrm{H}_{3} 5\right)$ and 1,3,5-tris(4-carboxyphenylethynyl)benzene $\left(\mathrm{H}_{3} 7\right)$, respectively. Successively, $\mathrm{K}_{3} \mathbf{5}$ and $\mathrm{K}_{3} 7$ were produced 345 quantitatively by treatment with potassium methoxide in methanol. The lithiation of $\mathbf{8}$ with $n$-BuLi followed by the reaction with $\mathrm{B}(\mathrm{OMe})_{3}$ gave 1,3,5-tris[4(dihydroxyboryl)phenylethynyl] benzene (9). The linkers, 1, 2, $3, \mathrm{~K}_{3} 5, \mathrm{H}_{3} 7, \mathrm{~K}_{3} 7$, and $\mathbf{9}$, synthesised in this section are 350 subjected to reaction with metal ions to form 2- or 3dimensional coordination polymers.
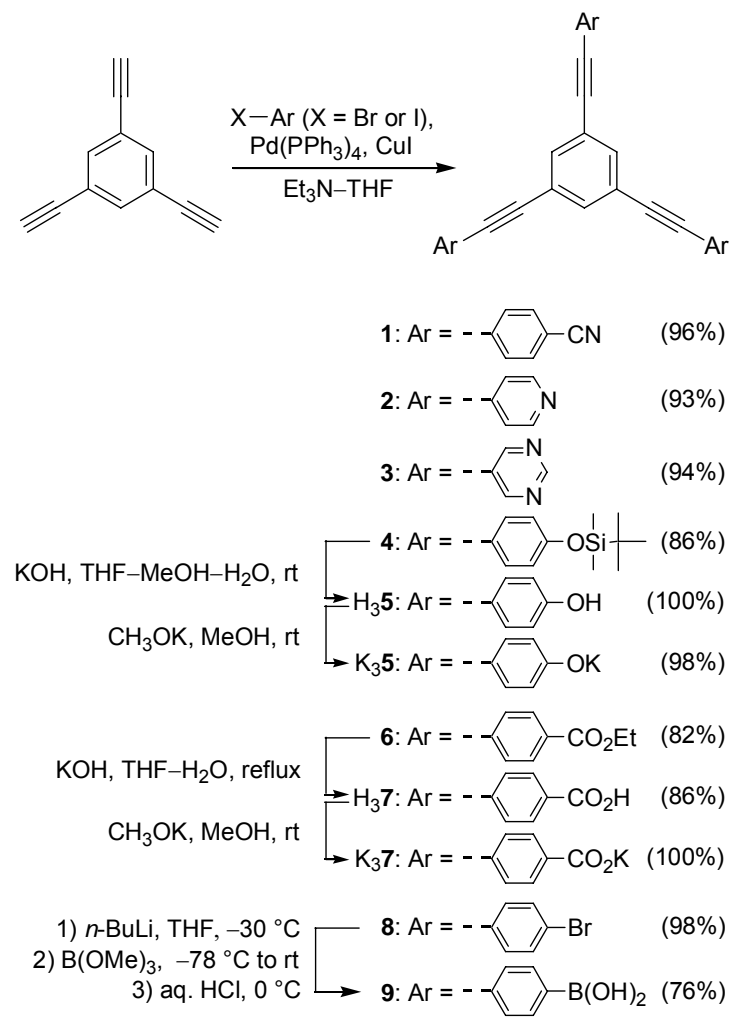

Scheme 1 Syntheses of functionalised 1,3,5-tris(substitutedphenylethynyl)benzenes.

\section{Carbonisation of organic linkers}

To investigate the carbonisation behavior of the organic linkers themselves, the compounds were carbonised by 355 heating up from room temperature to $900{ }^{\circ} \mathrm{C}$ at a rate of $5{ }^{\circ} \mathrm{C}$ $\min ^{-1}$ under flowing argon in a furnace, and then the surface analysis of the carbonised samples was carried out by $\mathrm{N}_{2}$ adsorption method. The $\mathrm{N}_{2}$ adsorption isotherms and the surface analysis data of the carbonised 1,3,5-tris(substituted360 phenylethynyl)benzenes (C-1-C-9) are summarised in Figure 2 and Table 1. All isotherms of $\mathbf{C - 1}-\mathbf{C}-\mathbf{9}$ show characteristic 
of type I according to IUPAC classification. ${ }^{30}$ The surface analysis data suggests that $\mathbf{C}-\mathbf{1}-\mathbf{C}-\mathbf{9}$ are microporous materials with average pore widths $\left(w_{\alpha}\right)$ of ca. $0.7 \mathrm{~nm}$ estimated from ${ }_{365}$ the $\alpha_{\mathrm{s}}$ plot by SPE method ${ }^{31}$ and have little meso- and macropores. The carbonisation yields of 1-9 were moderately high in the range of 53-83\%. Brunauer-Emmett-Teller (BET) surface areas $\left(A_{\mathrm{BET}}\right)$ of $\mathbf{C - 1}-\mathbf{C}-\mathbf{9}$ were scattering between 67 and $1040 \mathrm{~m}^{2} \mathrm{~g}^{-1}$. Since polymers have generally been used as 370 starting substances of carbon materials, it is interesting that such small-molecules show the high carbonisation yields and lead to the carbonaceous materials with high surface areas. Annealing at $900{ }^{\circ} \mathrm{C}$ is effective to develop microporosity in

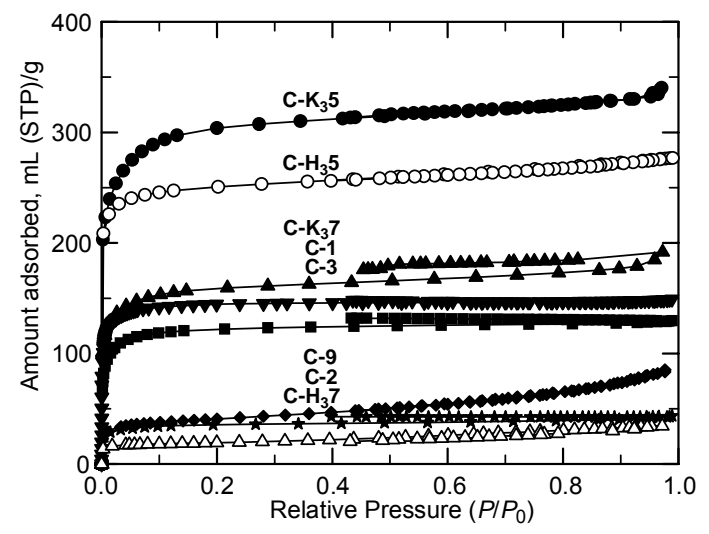

Fig. 2 Adsorption isotherms of nitrogen at $77 \mathrm{~K}$ for the carbonised (C)1,3,5-tris(substituted-phenylethynyl)benzenes (1-9).

Table 1 Surface parameters of C-1,3,5-tris(substitutedphenylethynyl)benzenes ${ }^{a}$

$\begin{array}{rcccccc}\text { sample yield } & A_{\mathrm{BET}}{ }^{b} / & V_{\text {total }}{ }^{c} / & V_{\text {micro }}{ }^{d /} & V_{\text {meso }} / V_{\text {total }}{ }^{e} & w_{\alpha}^{f} / \\ & (\%) & \mathrm{m}^{2} \mathrm{~g}^{-1} & \mathrm{~mL} \mathrm{~g}^{-1} & \mathrm{~mL} \mathrm{~g}^{-1} & (\%) & \mathrm{nm}\end{array}$

$$
\mathrm{m}^{2} \mathrm{~g}^{-1} \quad \mathrm{~mL} \mathrm{~g}^{-1} \quad \mathrm{mLg}^{-1} \quad(\%) \quad \mathrm{nm}
$$

$\begin{array}{rrrrrrr}\mathbf{1} & 82 & 495 & 0.23 & 0.22 & 1.2 & 0.72 \\ \mathbf{2} & 84 & 113 & 0.068 & 0.040 & 0.9 & 0.85 \\ \mathbf{3} & 70 & 459 & 0.20 & 0.19 & 0 & 0.74 \\ \mathrm{H}_{3} \mathbf{5} & 59^{g} & 840 & 0.43 & 0.37 & 7.0 & 0.64 \\ \mathrm{~K}_{3} \mathbf{5} & 56^{g} & 1040 & 0.59 & 0.45 & 6.5 & 0.78 \\ \mathrm{H}_{3} \mathbf{7} & 53^{g} & 67 & 0.054 & 0.025 & 38 & 0.68 \\ \mathrm{~K}_{3} \mathbf{7} & 53^{g} & 534 & 0.30 & 0.23 & 8.3 & 0.72 \\ \mathbf{9} & 77 & 150 & 0.13 & 0.048 & 37 & 0.71\end{array}$

${ }^{a}$ All the samples were carbonised by heating from r.t. to $900{ }^{\circ} \mathrm{C}$ at a heating rate of $5{ }^{\circ} \mathrm{C} \mathrm{min}^{-1}$. ${ }^{b}$ The surface area was estimated by the Brunauer-Emmett-Teller (BET) method. ${ }^{c}$ The total pore volume was estimated from the maximum adsorbed amount of $\mathrm{N}_{2}$ in the adsorption isotherm. ${ }^{d}$ The micropore volume was estimated by the $\alpha_{\mathrm{s}}$ method. ${ }^{e}$ The mesopore ratio was estimated by the Dollimore-Heal (DH) method. ${ }^{f}$ The average micropore width was determined by the $\alpha_{\mathrm{s}}$ plot and the SPE analysis. ${ }^{g}$ Annealed at $900{ }^{\circ} \mathrm{C}$ for $3 \mathrm{~h}$. particular in the case of C-5 and C-7 but is accompanied with 375 a considerable mass loss, which could be related to the degree of conversion from the amorphous carbon network material to the carbonised material that consists of the basic structure unit of carbonaceous layers. ${ }^{16 a} \mathbf{C}-\mathbf{H}_{3} \mathbf{7}, \mathbf{C}-2$ and $\mathbf{C}-\mathbf{9}$ showed low surface areas, which is probably due to an intermolecular 380 filling of the carbon precursors with softening properties during the pyrolysis. On the contrary, the potassium salts, C$\mathbf{K}_{3} 5$ and $\mathbf{C}-\mathrm{K}_{3} 7$, showed relatively high surface areas, because $\mathrm{K}_{3} 5$ and $\mathrm{K}_{3} 7$ were rigid solids with ionic interaction and, successively, $\mathrm{K}$ sublimed at around $760{ }^{\circ} \mathrm{C}$ after hardening of 385 the carbonaceous precursors.

\section{Synthesis and carbonisation of coordination polymers}

In order to narrow down the specific conditions for obtaining permanent porous coordination polymers by solution reaction, in the beginning a variety of coordination polymers was 390 prepared by a combinatorial reaction of the multicoordinated 1,3,5-tris(phenylethynyl)benzene derivatives with common transition metal salts such as $\mathrm{Cu}\left(\mathrm{CH}_{3} \mathrm{CO}_{2}\right)_{2}, \mathrm{CuCl}_{2} \cdot 2 \mathrm{H}_{2} \mathrm{O}$, $\mathrm{Cu}\left(\mathrm{NO}_{3}\right)_{2} \cdot 3 \mathrm{H}_{2} \mathrm{O}, \mathrm{Ni}\left(\mathrm{CH}_{3} \mathrm{CO}_{2}\right)_{2} \cdot 4 \mathrm{H}_{2} \mathrm{O}, \mathrm{Ni}\left(\mathrm{NO}_{3}\right)_{2} \cdot 6 \mathrm{H}_{2} \mathrm{O}$, and AgOTf. All metal-organic coordination polymers were 395 prepared from the slow intermixing method ${ }^{32}$ or rapid mixing method described in the experimental section. Chemically inert solvents such as 1,4-dioxane and THF were preferentially used in the preparations. All the coordination polymers were dried in vacuum at $80{ }^{\circ} \mathrm{C}$ for 12 hours, and 400 their empirical formulas of the complexes were estimated from the results of the elemental, ICP, and thermogravimetric analyses. The preparation conditions and the synthetic yields of $\mathbf{2 a - 7 e}$ are listed in the left quarter of Table $2 .{ }^{33}$ Majority of the coordination polymers were obtained in good yields over $40580 \%$. Considering the total yields (ca. 60\%) from the starting 1,3,5-tribromobenzene, it could be said that the synthetic procedure of these complexes are satisfactory for mass production of the coordination polymers.

In order to trace variation of the porosity through the 410 pyrolysis, surface analysis of the coordination polymers $\mathbf{2 a}-\mathbf{7 e}$, as-heat-treated carbonised samples, and acid-washed carbonised $\mathbf{C}-\mathbf{2 a}-\mathbf{C}-\mathbf{7 e}$ was carried out by $\mathrm{N}_{2}$ adsorption method. The yields in each process and the extracted data on the surface analysis are summarised in the right three quarters 415 of Table 2. Since the carbonised materials listed in Table 2 are basically microporous solids with mesoporosity in some degree, each adsorption volume such as $V_{\text {micro }}$ and $V_{\text {meso }}$ is roughly forecasted from the $A_{\mathrm{BET}}$ and the mesopore ratio $\left(V_{\text {meso }} / V_{\text {total }}\right)$. Most of the coordination polymers were low ${ }_{420}$ porous materials showing small $A_{\mathrm{BET}}$ below $50 \mathrm{~m}^{2} \mathrm{~g}^{-1}$, which suggests that it is hard to keep the network structure on the occasion of solvate removal. ${ }^{14 e, 34}$ Generally, MOFs constructed from a larger ligand tend to be less stable. ${ }^{13 \mathrm{c}}$ Hence, utilisation of a strong metal-linker bond is desirable to ${ }_{425}$ form a variety of MOFs with a stable porous structure. ${ }^{35}$ Actually, 7c-7e prepared from the conjugated carboxylate linker $\mathrm{K}_{3} 7$ with copper ions had considerable permanent total pore volumes $\left(V_{\text {total }}\right), 0.261,0.469$, and $0.266 \mathrm{~mL} \mathrm{~g}^{-1}$, respectively, which suggests that a large linker 7, 1,3,5-tris[4430 carboxyphenylethynyl]benzene, is notably adapted to construct stable MOFs. 
Table 2 Preparations of coordination polymers, and surface parameters of the complexes, carbonised samples acid-washed carbons

synthesis $\quad$ complex $(\mathbf{2 a}-\mathbf{7 e}) \quad$ as-prepared carbon ${ }^{c}$

linker metal salt solvent $^{a} \quad$ yield complex $A_{\mathrm{BET}} / \quad V_{\text {total }}^{b}$

$\quad \mathrm{m}^{2} \mathrm{~g}^{-1} \quad \mathrm{~mL} \mathrm{~g}^{-1}$ carbonisation $A_{\mathrm{BET}} / \quad V_{\text {meso }} / V_{\text {total }}{ }^{d}$ yield $(\%) \quad \mathrm{m}^{2} \mathrm{~g}^{-1} \quad(\%)$ acid-washed carbon (C-2a-C-7e)

acid-washed $A_{\mathrm{BET}} / \quad V_{\text {meso }} / V_{\text {total }}{ }^{d}$ yield (\%) $\quad \mathrm{m}^{2} \mathrm{~g}^{-1}$

$(\%)$

\begin{tabular}{|c|c|c|c|c|c|c|c|c|c|c|c|c|}
\hline 2 & $\mathrm{Cu}\left(\mathrm{CH}_{3} \mathrm{CO}_{2}\right)_{2}$ & diox & 96 & $2 \mathbf{a}$ & 2 & 0.012 & 51 & 434 & 3.2 & 74 & 453 & 17 \\
\hline 2 & $\mathrm{CuCl}_{2} \cdot 2 \mathrm{H}_{2} \mathrm{O}$ & diox & 84 & $2 \mathbf{b}$ & 7 & 0.037 & 65 & 568 & 14 & 68 & 624 & 9.4 \\
\hline 2 & $\mathrm{Cu}\left(\mathrm{NO}_{3}\right)_{2} \cdot 3 \mathrm{H}_{2} \mathrm{O}$ & diox-THF & 60 & 2c & 12 & 0.046 & 35 & 343 & 50 & 46 & 780 & 23 \\
\hline 3 & $\mathrm{CuCl}_{2} \cdot 2 \mathrm{H}_{2} \mathrm{O}$ & diox & 85 & 3a & 2 & 0.013 & $47^{e}$ & & & 53 & 910 & 11 \\
\hline $\mathrm{H}_{3} 7$ & $\mathrm{Cu}\left(\mathrm{NO}_{3}\right)_{2} \cdot 3 \mathrm{H}_{2} \mathrm{O}$ & diox-THF & 92 & $7 a$ & 15 & 0.052 & 69 & 552 & 9.4 & 78 & 584 & 30 \\
\hline $\mathrm{H}_{3} 7$ & $\mathrm{Cu}\left(\mathrm{CH}_{3} \mathrm{CO}_{2}\right)_{2}$ & diox & 88 & $7 \mathbf{b}$ & 37 & 0.164 & $60^{e}$ & & & 78 & 584 & 30 \\
\hline $\mathrm{K}_{3} 7$ & $\mathrm{Cu}\left(\mathrm{CH}_{3} \mathrm{CO}_{2}\right)_{2}$ & $\mathrm{MeOH}$ & 86 & 7c & 105 & 0.261 & $68^{e}$ & 724 & 38 & 67 & 1250 & 30 \\
\hline $\mathrm{K}_{3} 7$ & $\mathrm{CuCl}_{2} \cdot 2 \mathrm{H}_{2} \mathrm{O}$ & $\mathrm{MeOH}$ & 89 & $7 d$ & 104 & 0.469 & $67^{e}$ & 600 & 48 & 70 & 736 & 50 \\
\hline $\mathrm{K}_{3} 7$ & $\mathrm{Cu}\left(\mathrm{NO}_{3}\right)_{2} \cdot 2 \mathrm{H}_{2} \mathrm{O}$ & $\mathrm{DMF}-\mathrm{MeOH}$ & 95 & $7 e$ & 444 & 0.266 & 63 & 586 & 34 & 68 & 747 & 27 \\
\hline
\end{tabular}

${ }^{a}$ diox $=1,4$-dioxane. ${ }^{b}$ Estimated from the maximum adsorbed volume. ${ }^{c}$ All the samples were treated at a heating rate of $5{ }^{\circ} \mathrm{C}$ min ${ }^{-1}$ to $900{ }^{\circ} \mathrm{C} .{ }^{d}$ Estimated by the DH method..$^{e}$ Annealed at $900^{\circ} \mathrm{C}$ for $3 \mathrm{~h}$.

After the carbonisation of $\mathbf{2 a - 7 e , ~ t h e ~ a s - h e a t - t r e a t e d ~}$ materials were washed with $8 \mathrm{M} \mathrm{HNO}_{3}$ to remove the isolated copper that was sintered on the surface during pyrolysis, 435 affording the acid-washed carbons, C-2a-C-7e. Removal of the sintering metal on the surface by the posttreatment was confirmed by disappearance of the XRD diffraction peaks of the metal. The difference between the $A_{\mathrm{BET}}$ of the acid-washed carbonised materials and those simply estimated from the ${ }_{440} A_{\mathrm{BET}}$ of the as-heated samples and the yields of acid-washing (shown in Table 2) suggests the presence of a considerable amount of metal included in the materials.

For representative example, $\mathrm{N}_{2}$ adsorption isotherms of the low-porous coordination polymers 2c, 3a, microporous MOF $445 \mathbf{7 e}$, and their acid-washed carbonised samples $\mathbf{C - 2 c}, \mathbf{C}-3 \mathbf{3}, \mathbf{C}-$

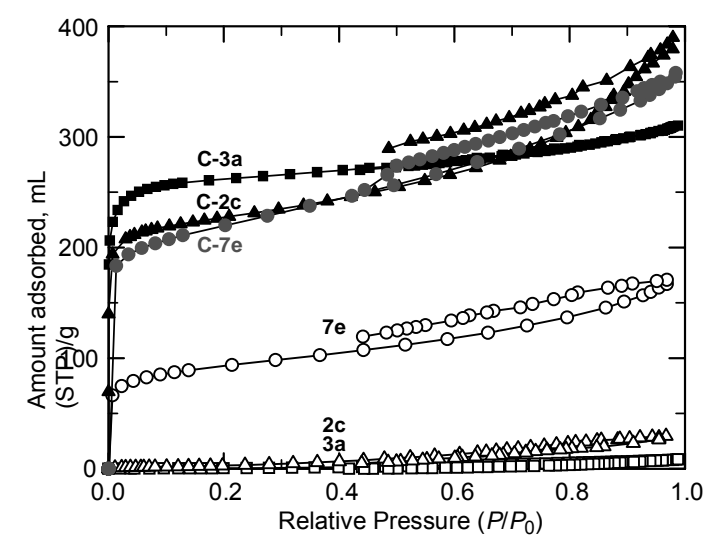

Fig. $3 \mathrm{~N}_{2}$ adsorption isotherms of the coordination polymers (low porous 2c, 3a, microporous 7e), and their carbonised (C-) samples. 7e are depicted in Figure 3. The $A_{\mathrm{BET}}$ of $\mathbf{C - 2 c}, \mathbf{C}-\mathbf{3 a}$, and $\mathbf{C}-\mathbf{7 e}$ (780, 910, and $\left.747 \mathrm{~m}^{2} \mathrm{~g}^{-1}\right)$ were considerably larger than those of 2c, 3a, and 7e $\left(12,2\right.$, and $\left.333 \mathrm{~m}^{2} \mathrm{~g}^{-1}\right)$. The increase of $A_{\mathrm{BET}}$ is considered to be reasonable, because 2, 3, and $\mathrm{K}_{3} 7$ 450 (the linkers of $\mathbf{2 c}, \mathbf{3 a}$, and $\mathbf{7 e}$, respectively) were pyrolysed to a microporous carbon as shown in Figure 2 and Table 1. Nevertheless, it should be noted that the $A_{\mathrm{BET}}$ of all the acidwashed carbonised samples C-2a-C-7e (Table 2) were larger than those of corresponding carbonised linkers (Table 1).

${ }_{455}$ Hence, constructing a coordination network in advance must be available to prepare a porous carbon with a high porosity, even if the coordination polymer is low-porous or nonporous. On the other hand, the mesopore volumes $\left(V_{\text {meso }}\right)$ of $\mathbf{2 c}, \mathbf{3 a}$, and $7 \mathrm{e}\left(0.036,0.012\right.$, and $\left.0.078 \mathrm{~mL} \mathrm{~g}^{-1}\right)$ were almost

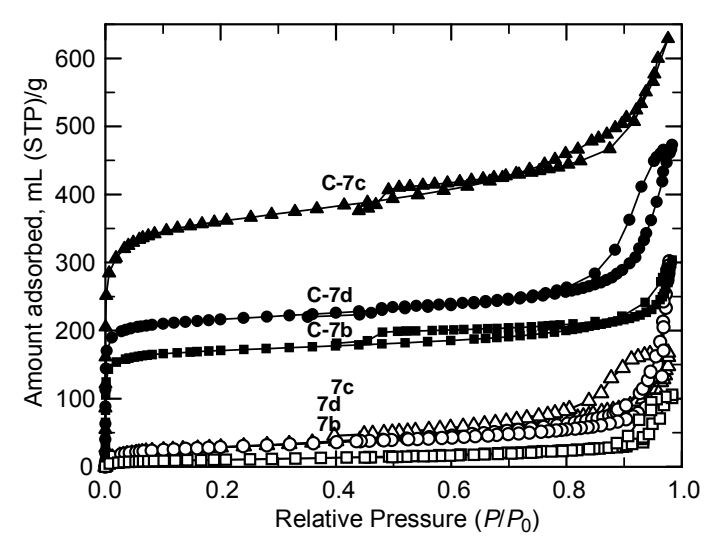

Fig. $4 \mathrm{~N}_{2}$ adsorption/desorption isotherms of the mesoporous coordination polymers and their carbonised samples. 
460 equivalent to the $V_{\text {meso }}$ of their carbonised samples, C-2c, C3a, and $\mathbf{C}-7 \mathbf{e}\left(0.14,0.055\right.$, and $\left.0.15 \mathrm{~mL} \mathrm{~g}^{-1}\right)$. In the $P / P_{0}$ range of $0.4-1$, the shape of isotherms of all samples before and after carbonisation is similar to each other, which indicates that the coordination polymers retain the meso- and 465 macroporosity through the pyrolysis. Origin of the mesoporosity must be interspaces of aggregated nanoparticles as well as mesoporous polymer gels and carbonised ones. ${ }^{36}$

In this work, three mesoporous coordination polymers, $\mathbf{7 b}$, $\mathbf{7 c}$, and $\mathbf{7 d}$, were obtained by the solution reaction of $\mathbf{7}$ with 470 copper salts. The $\mathrm{N}_{2}$ adsorption isotherms of $\mathbf{7 b}, \mathbf{7 c}$, and $\mathbf{7 d}$ are shown in Figure 4 together with the acid-washed carbonised samples $\mathbf{C - 7 b}, \mathbf{C - 7 d}$ and $\mathbf{C - 7 c}$. In analogy with the low-porous coordination poymers, increases of $V_{\text {micro }}$ and retainment of the mesoporous features were observed through 475 the carbonisation with no exceptions. Exhibiting the steep $\mathrm{N}_{2}$ uptakes at a high relative pressure $\left(P / P_{0}\right)$ and the hysteresis loop extending from 0.8 to 1 in $P / P_{0}$ provides an evidence of existence of large mesopores. As a consequence, atypical porous carbons that have both of the mesoporosity of the 480 coordination polymers and the microporosity of carbonised organic linkers were created. The $V_{\text {total }}$ of $\mathbf{C - 7 b}, \mathbf{C - 7 d}$ and $\mathbf{C}-$ 7c came to $0.47,0.98,0.74 \mathrm{~mL} \mathrm{~g}^{-1}$, respectively. These values are comparable to the porosity of carbon gels ${ }^{36}$ which are a representative advanced mosoporous carbon.

${ }_{485}$ Pyrolytic carbonisation behavior of mesoporous coordination polymer

In order to confirm that the mesoporosity of the carbonised coordination polymers $\mathbf{C}-\mathbf{7} \mathbf{b}-\mathbf{d}$ were derived from those of pre-carbonised ones, a stepwise pyrolysis of 7c that showed 490 type IV adsorption-desorption isotherm was performed at $350{ }^{\circ} \mathrm{C}(\mathbf{7 c}(\mathbf{3 5 0})), 600^{\circ} \mathrm{C}(\mathbf{7 c}(\mathbf{6 0 0}))$, and $900^{\circ} \mathrm{C}(\mathbf{7 c}(\mathbf{9 0 0}))$. Their surface analyses by $\mathrm{N}_{2}$ adsorption method, XRD, and SEM were carried out in this section.

The $\mathrm{N}_{2}$ adsorption-desorption isotherms are shown in 495 Figure 5, and the surface parameters are listed in Table 3. The specific surface areas monotonically increased in sequence of $\mathbf{7 c}<\mathbf{7 c}(\mathbf{3 5 0 )}<\mathbf{7 c ( 6 0 0 )}<\mathbf{7 c}(\mathbf{9 0 0})<\mathbf{7 c}(\mathbf{9 0 0}, 3 \mathrm{~h})$ as raising the heat treatment temperature. In the case of pyrolysis of conjugated polymers that have carbon-carbon triple bond, a

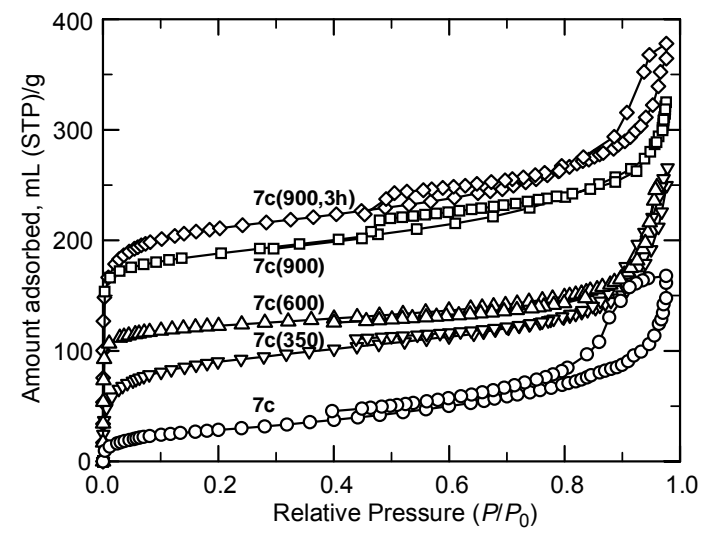

Fig. $5 \mathrm{~N}_{2}$ adsorption/desorption isotherms of the mesoporous coordination polymer $7 \mathbf{e}$ and the heat-treated samples at $350,600,900{ }^{\circ} \mathrm{C}$, and $900{ }^{\circ} \mathrm{C}$ for $3 \mathrm{~h}$.
Table 3 Surface parameters of 7c, heat-treated samples, and acid-washed C-7c $\mathbf{c}^{a}$

$\begin{array}{cccccc}\text { temperature } & A_{\mathrm{BET}} / & V_{\text {total }} / & V_{\text {micro }} / & V_{\text {meso }} / & w_{\alpha} / \\ \left({ }^{\circ} \mathrm{C}\right) & \mathrm{m}^{2} \mathrm{~g}^{-1} & \mathrm{~mL} \mathrm{~g}^{-1} & \mathrm{~mL} \mathrm{~g}^{-1} & \mathrm{~mL} \mathrm{~g}^{-1} & \mathrm{~nm} \\ 900^{b} & 1250 & 0.98 & 0.22 & 0.30 & 0.74 \\ 900^{c} & 724 & 0.59 & 0.27 & 0.22 & 0.73 \\ 900 & 637 & 0.51 & 0.23 & 0.15 & 0.61 \\ 600 & 419 & 0.38 & 0.16 & 0.19 & 0.65 \\ 350 & 320 & 0.41 & 0.11 & 0.20 & 1.0 \\ 80^{d} & 105 & 0.26 & 0.057 & 0.19 & \mathrm{NA}^{e}\end{array}$

${ }^{a}$ All the samples were treated at a heating rate of $5^{\circ} \mathrm{C} \min ^{-1}$. The $V_{\text {total }}$ was estimated from the maximum adsorbed volume, and the $V_{\text {meso }}$ was estimated by the DH method. The $V_{\text {micro }}$ and $w_{\alpha}$ were determined by the $\alpha_{\mathrm{s}}$ plots. ${ }^{b} \mathbf{C - 7 c}$, the acid-washed carbon obtained from $\mathbf{7 c}(\mathbf{9 0 0 , 3 h}) .^{c}$ Annealed at $900{ }^{\circ} \mathrm{C}$ for 3 h. ${ }^{d} \mathbf{7 c}$, as-prepared complex. ${ }^{e}$ Not applicable.

500 specific surface area begins to increase when the temperature is above $500{ }^{\circ} \mathrm{C},{ }^{37}$ which is different from the tendency observed in 7c. TG/DTA of 7c (shown in ESI Figure S4) showed an exothermal peak accompanied by a mass loss at around $300{ }^{\circ} \mathrm{C}$, which is due to decomposition or elimination 505 of the counter acetate anion. Therefore, the unexpected increase of the $A_{\mathrm{BET}}$ of $7 \mathrm{c}$ when heat-treated at $350^{\circ} \mathrm{C}$ (7c(350)) could be due to desorption of the acetate anion from the original building construction. On the contrary, the $V_{\text {meso }}$ of 7c $\left(c a .0 .2 \mathrm{~mL} \mathrm{~g}^{-1}\right)$ remained unchanged during the heat510 treatment from the starting temperature to $900{ }^{\circ} \mathrm{C}$. These results mean that the mesoporosity of the mesoporous coordination polymer was kept during the process of transformimg to a microporous carbon by heat-treatment.

The generation process of the microporosity and the ${ }_{515}$ thermal behavior of the inclusion metal are traced by XRD analysis. The XRD patterns of the coordination polymer 7c, the heat-treated samples at different temperatures, and the

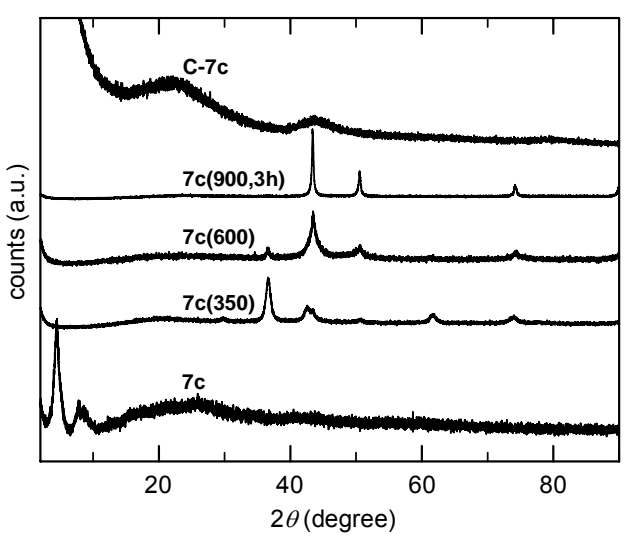

Fig. 6 XRD patterns of 7c, heat-treated samples, and the acid-washed C7c. 


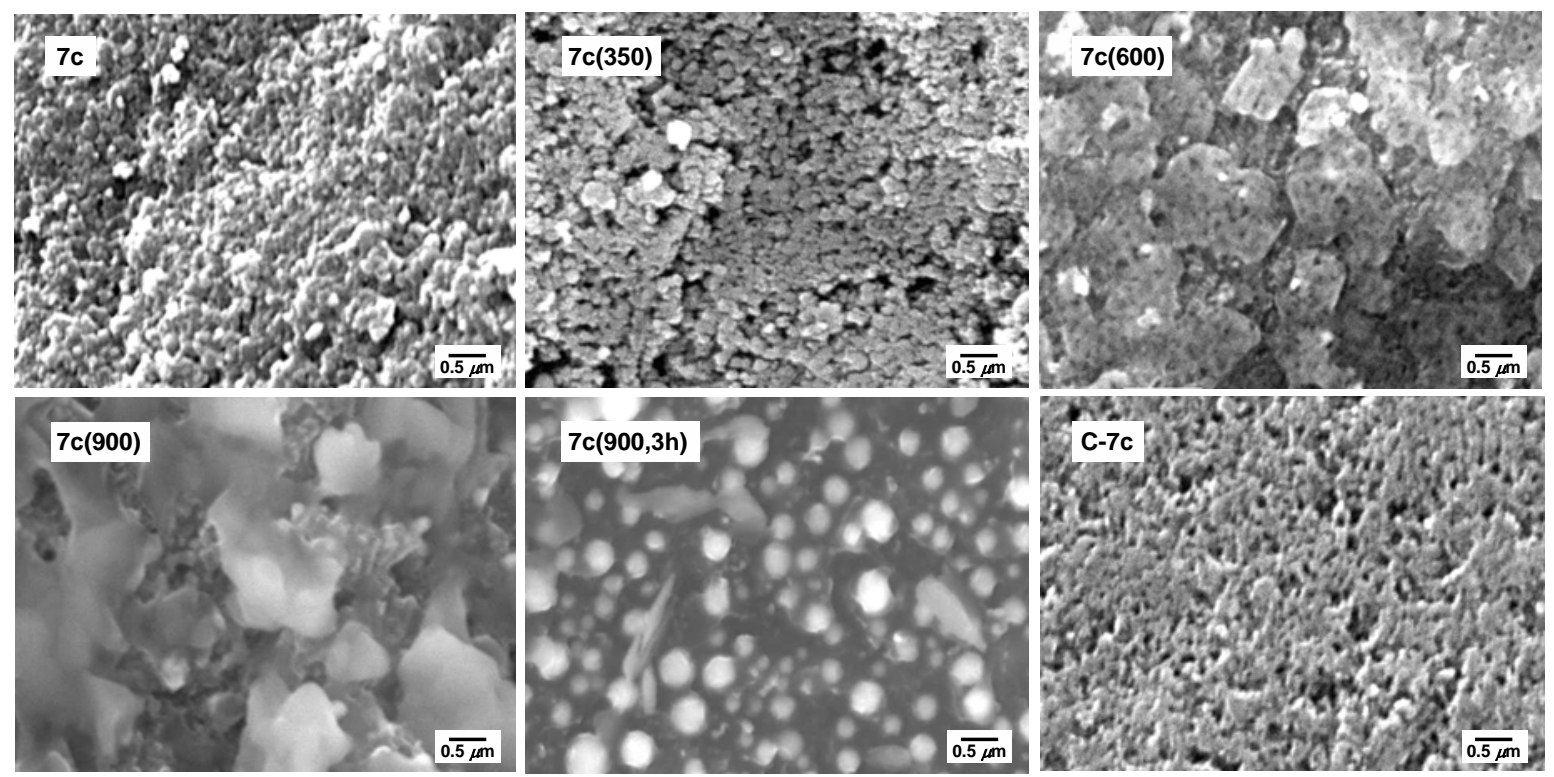

Fig. 7 SEM images of 7c, the heat-treated samples, and the acid-washed C-7c.

acid-washed carbonised sample C-7c are shown in Figure 6. The coordination polymer $7 \mathbf{c}$ has diffraction peaks at $2 \theta=$ ${ }_{520} 4.5^{\circ}$ and $7.9^{\circ}$, which suggests that $7 \mathbf{c}$ has a periodic structure with 2.0 and $1.0 \mathrm{~nm}$ distances as well as the microporous carbon synthesised by a template method. ${ }^{38}$ The original diffraction peaks were completely lost under the heat treatment by $350{ }^{\circ} \mathrm{C}$. At the same time, peaks of isolated

525 copper (I) indexing $\mathrm{Cu}_{2} \mathrm{O}$ newly appeared in $7 \mathbf{c}(350)$. The periodic microporous structure of $7 \mathrm{c}$ could be disarranged by the increase of microporosity with the elimination of acetate during the pyrolysis. In the case of $\mathbf{7 c ( 6 0 0 )}$, diffraction peaks of copper (0) appeared instead of the peaks of $\mathrm{Cu}_{2} \mathrm{O}$, which 530 was attributed to reduction by carbon. The $\mathrm{Cu}$ peaks became sharper by the heat-treatment at $900{ }^{\circ} \mathrm{C}$, which indicates that the particle size of the isolated metal grows larger. In the case of $\mathbf{C - 7 c}$, the peaks of isolated copper observed in $\mathbf{7 c}(\mathbf{9 0 0}, \mathbf{3 h})$ completely disappeared by leaching with nitric acid, and the

${ }_{535}$ broad peaks of carbon became apparent. Dimensions of the basic structure unit of carbon perpendicular and parallel to the basal plane and graphitic interlayer spacing were estimated from the (002) and (110) diffraction peaks by means of the Bragg formula and Scherrer equation ${ }^{39}$ to be $1.6 \mathrm{~nm}\left(L_{\mathrm{c}}\right), 2.5$ $540 \mathrm{~nm}\left(L_{\mathrm{a}}\right)$, and $0.40 \mathrm{~nm}\left(d_{\mathrm{i}}\right)$, respectively. The large $d_{\mathrm{i}}$ and small $L$ values for C-7c are comparable to the hard carbon derived from the conjugated polymers ${ }^{16,34}$ and are different from graphitic materials such as carbon black. ${ }^{40}$ Additionally, the acid-washed C-7c must include a highly dispersed copper, 545 since the presence of copper $(0.63 \mathrm{wt} \%)$ in $\mathbf{C}-7 \mathrm{c}$ was confirmed by ICP analysis despite XRD peaks of $\mathrm{Cu}$ were not observed.

At the last, the change of the surface morphology is checked by SEM. Figure 7 shows the SEM images of the 550 coordination polymer $\mathbf{7 c}$, the heat-treated samples at different temperatures, and the acid-washed C-7c. The surface morphology of 7c suggests presence of aggregates consisted of particles having an average diameter of $c a .100 \mathrm{~nm}$. The mesopores that should be interspaces between the aggregated ${ }_{555}$ particles are observed as countless black dots with a hole diameter smaller than $50 \mathrm{~nm}$. The nano-particles seem to be gradually agglomerated as raising the heat-treated temperatures, and the size of the agglomerations observed in $\mathbf{7 c ( 6 0 0 )}$ came to the range of micron scales. The 560 agglomeration is due to leaching out of the metal salt and following metalation on the surface, and the black dots can be observed unchanged. After the agglomeration, a thin layer metal covered the surface of $\mathbf{7 c}(\mathbf{9 0 0})$, and successively the sintering metal grew to about $250 \mathrm{~nm}$-sized particles on the 565 surface of $\mathbf{7 c}(\mathbf{9 0 0}, \mathbf{3 h})$. The surface of $\mathbf{C - 7 c}$ renovated by acidwashing using nitric acid showed a morphology similar to those observed in $\mathbf{7 c}$ and $\mathbf{7 c ( 3 5 0 )}$. This result supports that the mesoporosity of $\mathbf{7 c}$ is hardly changed by the pyrolysis process which has already been observed in the $\mathrm{N}_{2}$ adsorption analysis 570 (Figure 5 and Table 3).

\section{Conclusion}

In this paper, we have demonstrated a novel strategy to prepare porous carbons from coordination polymers. For this 575 purpose, we initially explored a thermally stable organic linker, and found that 1,3,5-tris(phenylethynyl)benzene derivatives could be carbonised in a high yield through a mild pyrolytic process without bringing about rapid and large structural changes. Then various types of 1,3,5580 tris(functionalised-phenylethynyl)benzenes 1-9 were synthesised, and successively reacted with metal ions to construct coordination polymers. Althogh most of the coordination polymers synthesised by the solution reaction method are low porous materials, those synthesised from ${ }_{585}$ tricarboxy $\mathrm{K}_{3} 7$ as the linker exceptionally show either microporosity or mesoporosity.. Nevertheless, the 
coordination polymers can be transformed to microporous carbons by pyrolysis without exception even if the pre-carbon materials are low-porous or nonporous, beause the organic 590 linkers 1-9 themselves can be converted to microporous carbons by pyrolysis. Consequently, the carbonised coordination polymers have higher porosity than the carbonised organic linkers. On the other hand, it was found that mesoporosity of the coordination polymers are hardly 595 changed by the pyrolytic processes. Thus, it is realised that mesoporous coordination polymers can be converted to mesoporous carbons with microporosity.

\section{Acknowledgements}

600 This work was supported by a JSPS Research Fellowships (No. 18.3824) and Ogasawara Foundation. We thank to the Research Facility Center for Science and Technology, Chemical Analysis Division, University of Tsukuba, for NMR, ICP, elemental, thermal, and surface analysis data.

605

\section{Notes and references}

1 (a) M. L. K. Hoa, M. Lu and Y. Zhang, Adv. Colloid and Interface Sci., 2006, 121, 9; (b) F. Fajula, A. Galarneau amd F. D. Renzo, Microporous Mesoporous Mater., 2005, 82, 227; (c) M. E. Davis, $610 \quad$ Nature (London), 2002, 417, 813.

2 J. Lee, J. Kim and T. Hyeon, Adv. Mater., 2006, 18, 2073.

3 (a) Y. Tao, H. Kanoh, L. Abrams and K. Kaneko, Chem. Rev., 2006, 106, 896; (b) E. S. Toberer and R. Seshadri, Chem. Commun., 2006, 3159 .

6154 (a) S. Kitagawa, R. Kitaura and S. Noro, Angew. Chem. Int. Ed., 2004, 43, 2334; (b) J. L. C. Rowsell and O. M. Yaghi, Microporous Mesoporous Mater., 2004, 73, 3; (c) M. J. Rosseinsky, Microporous Mesoporous Mater., 2004, 73, 15.

5 (a) Z. Yang, Y. Xia and R. Mokaya, J. Am. Chem. Soc., 2007, 129,

620 1673; (b) M. Jordá-Beneyto, F. Suárez-García, D. Lozano-Castelló, D Cazorla-Amorós and A. Linares-Solano, Carbon, 2007, 45, 293.

6 (a) P. S. Tin, T.-S. Chung, L. Jiang and S. Kulprathipanja, Carbon, 2005, 43, 2025; (b) K. M. Steel and W. J. Koros, Carbon, 2003, 41, 253.

6257 (a) S.-I. Kim, T. Yamamoto, A. Endo, T. Ohmori and M. Nakaiwa, Microporous Mesoporous Mater., 2006, 96, 191; (b) S.-D. Bae, M. Sagehashi and A. Sakoda, Carbon, 2003, 41, 2973; (c) C. FaurBrasquet, K. Kadirvelu and P. Le Cloirec, Carbon, 2002, 40, 2387.

8 (a) W. Han, H. Liu and H. Zhu, Catal. Commun., 2007, 8, 351; (b) C.

630 Moreno-Castilla and F. J. Maldonado-Hódar, Carbon, 2005, 43, 455; (c) R. J. Willey, C. T. Wang and J. B. Peri, J. Non-Cryst. Solids, 1995, 186, 408.

9 (a) Y. Wang, H. C. Zeng and J. Y. Lee, Adv. Mater., 2006, 18, 645; (b) I. Grigoriants, L. Sominski, H. Li, I. Ifargan and D. Aurbach, A. Gedanken, Chem. Commun., 2005, 921.

10 (a) H. Yamada, H. Nakamura, F. Nakahara, I. Moriguchi and T. Kubo, J. Phys. Chem. C, 2007, 111, 227; (b) J. C. Famer, D. V. Fix, G. V. Mack, R. W. Pekala and J. F. Poco, J. Electrochem. Soc., 1996, 143, 159; (c) S. T. Mayer, R. W. Pekala and J. L. Kaschmitter, J. Electrochem. Soc., 1993, 140, 446.

11 (a) Z. Hu, M. P. Srinivasan and Y. Ni, Adv. Mater., 2000, 12, 62; (b) R. Torregrosa-Maciá, J. M. Martín-Martínez and M. C. MittelmeijerHazeleger, Carbon, 1997, 35, 447.

12 (a) M. Sevilla and A. B. Fuertes, Carbon, 2006, 44, 468; (b) B.

645 Sakintuna and Y. Yürüm, Ind. Eng. Chem. Res., 2005, 44, 2893; (c) K. Jurewicz, C. Vix-Guterl, E. Frackowiak, S. Saadallah, M. Reda, J. Parmentier, J. Patarin and F. Béguin, J. Phys. Chem. Solids, 2004, 65, 287; (d) Z. Ma, T. Kyotani and A. Tomita, Carbon, 2002, 40, 2367; (e) S. B. Yoon, J. Y. Kim and J.-S. Yu, Chem. Commun., 2001, 559; (f) R. Ryoo, S. H. Joo and S. Jun, J. Phys. Chem. B, 1999, 103, 7743.

13 (a) R.-Q. Zou, H. Sakurai and Q. Xu, Angew. Chem., Int. Ed., 2006, 45, 2542; (b) C.-D. Wu, L. Zhang and W. Lin, Inorg. Chem., 2006, 45, 7278; (c) Y. Ke, D. J. Collins, D. Sun and H.-C. Zhou, Inorg. Chem., 2006, 45, 1897; (d) N. L. Rosi, J. Kim, M. Eddaoudi, B. Chen, 655 M. O'Keeffe and O. M. Yaghi, J. Am. Chem. Soc., 2005, 127, 1504; (e) M. O'Keeffe and O. M. Yaghi, Nature, 2004, 427, 523.

14 (a) S. Ma, D. Sun, M. Ambrogio, J. A. Fillinger, S. Parkin and H.-C. Zhou, J. Am. Chem. Soc., 2007, 129, 1858; (b) B. D. Chandler, D. T. Cramb and G. K. H. Shimizu, J. Am. Chem. Soc., 2006, 128, 10403; (c) M. Dincă, A. F. Yu and J. R. Long, J. Am. Chem. Soc., 2006, 128, 8904; (d) D. Sun, S. Ma, Y. ke, D. J. Collins and H.-C. Zhou, J. Am. Chem. Soc., 2006, 128, 3896; (e) D. Sun, Y. Ke, T. M. Mattox, S. Parkin and H-C. Zhou, Inorg. Chem., 2006, 45, 7566; (f) L. Alaerts, E. Séguin, H. Poelman, F. Thibault-Starzyk, P. A. Jacobs and D. E. D 665 Vos, Chem.-Eur. J., 2006, 12, 7353; $(g)$ D. Sun, D. J. Collins, Y. Ke, J.-L. Zuo and H.-C. Zhou, Chem.-Eur. J., 2006, 12, 3768; (h) A. C. Sudik, A. P. Côté, A. G. Wong-Foy, M. O'Keeffe and O. M. Yaghi, Angew. Chem., Int. Ed., 2006, 45, 2528; (i) X.-C. Huang, Y.-Y. Lin, J.-P. Zhang and X.-M. Chen, Angew. Chem., Int. Ed., 2006, 45, 1557.

67015 X.-S. Wang, S. Ma, D. Sun, S. Parkin and H.-C. Zhou, J. Am. Chem. Soc., 2006, 128, 16474.

16 (a) M. Kijima, H. Tanimoto, K. Takakura, D. Fujiya, Y. Ayuta and K. Matsuishi, Carbon, 2007, 45, 594; (b) M. Kijima, T. Oda, T. Yamazaki, Y. Tazaki and J. Nakamura, Chem. Lett., 2006, 35, 844; 675 (c) M. Kijima, H. Tanimoto and H. Shirakawa, Synth. Met., 2001, 119, 353; (d) M. Kijima, H. Tanimoto, H. Shirakawa, A. Oya, T.-T. Liang and Y. Yamada, Carbon, 2001, 39, 297.

17 (a) N. Kobayashi and M. Kijima, J. Mater. Chem., 2007, 17, 4289. (b) J.-X. Jiang, F. Su, A. Trewin, C. D. Wood, N. L. Campbell, H. 680 Niu, C. Dickinson, A. Y. Ganin, M. J. Rosseinsky, Y. Z. Khimyak and A. I. Cooper, Angew. Chem., Int. Ed., 2007, 46, 8574.

18 K. Kobayashi and N. Kobayashi, J. Org. Chem., 2004, 69, 2487.

19 K. Kobayashi, N. Kobayashi, M. Ikuta, B. Therrien, S. Sakamoto and K. Yamaguchi, J. Org. Chem., 2005, 70, 749.

68520 (a) M. El-Merraoui, H. Tamai, H. Yasuda and T. Kanata, Carbon, 1998, 36, 1769; (b) N. Setoyama, T. Suzuki and K. Kaneko, Carbon, 1998, 36, 1459; (c) K. Kaneko, C. Ishii, M. Ruike and H. Kuwabara, Carbon, 1992, 30, 1075; (d) D. Dollimore and G. R. Heal, J. Colloid Interface Sci., 1970, 33, 508.

69021 J. Nierle, D. Barth and D. Kuck, Eur. J. Org. Chem., 2004, 4, 867.

22 F. Wang; B. R. Kaafarani and D. C. Neckers, Macromolecules, 2003, 36, 8225

23 Y. Hu, T. Sakaguchi, M. Shiotsuki, F. Sanada and T. Masuda, J. Membr. Sci., 2006, 282, 423.

69524 Y. Yamaguchi, T. Ochi, S. Miyamura, T. Tanaka, S. Kobayashi, T. Wakamiya, Y. Matsubara and Z. Yoshida, J. Am. Chem. Soc., 2006, 128, 4504 .

25 P. J. Stang and B. Olenyuk, Organometallics, 1997, 16, 3094.

26 R. K. Castellano and J., Jr. Rebek, J. Am. Chem. Soc., 1998, 120, 3657.

27 (a) K. Kobayashi, A. Sato, S. Sakamoto and K. Yamaguchi, J. Am. Chem. Soc., 2003, 125, 3035; (b) K. Kobayashi, T. Shirasaka, E. Horn and N. Furukawa, Tetrahedron Lett., 2000, 41, 89; (c) K. Kobayashi, T. Shirasaka, A. Sato, E. Horn and N. Furukawa, Angew. Chem., Int. Ed. Engl., 1999, 38, 3483.

28 (a) N. Treitel, L. Eshdat, T. Sheredsky, P. M. Donovan, R. R. Tykwinski, L. T. Scott, H. Hopf and M. Rabinovitz, J. Am. Chem. Soc., 2006, 128, 4703; (b) R. R. Jones and R. G. Bergman, J. Am. Chem. Soc., 1972, 94, 660.

71029 (a) S. Takahashi, Y. Kuroyama, K. Sonogashira and N. Hagihara, Synthesis, 1980, 627; (b) K. Sonogashira, In Metal-catalyzed Crosscoupling Reactions; F. Diederich, P. J. Stang, Eds.; Wiley-VCH: Weinheim, Germany, 1998; Chapter 5.

30 F. Izumi and T. Ikeda, Mater. Sci. Forum., 2000, 198, 321.

71531 K. Kaneko, C. Ishii, H. Kanoh, Y. Hanzawa, N. Setoyama and T. Suzuki, Adv. Colloid Interface Sci., 1998, 76-77, 295.

32 S. Masaoka, D. Tanaka, H. Kitahata, S. Araki, R. Matsuda, K. Yoshikawa, K. Kato, M. Takata and S. Kitagawa, J. Am. Chem. Soc., 2006, 128, 15799. 
72033 For all data including Ni and Ag linked coordination polymers, see the electronic supplementary information (Tables S1 and S2).

34 (a) D. T. de Lill, N. S. Gunning and C. L. Cahill, Inorg. Chem, 2005, 44, 258; (b) Z.-H. Zhang, Z.-L. Shen, T. Okamura, H.-F. Zhu, W.-Y. Sun and N. Ueyama, Crist. Growth Des., 2005, 5, 1191; (c) E. Y. Lee and M. P. Suh, Angew. Chem., Int. Ed. Engl., 2004, 43, 2798.

35 M. P. Suh, H. J. Choi, S. M. So and M. Kim, Inorg. Chem., 2003, 42, 676.

36 (a) N. Tonanon, A. Siyasukh, W. Tanthapanichakoon, H. Nishihara, S. R. Mukai and H. Tamon, Carbon, 2005, 43, 525; (b) R. W. Pekala, J. Mater. Sci., 1989, 24, 3221

37 M. Kijima, D. Fujiya, T. Oda and M. Ito, J. Therm. Anal. Calorim., 2005, 81, 549 .

38 A. Garsuch and O. Klepel, Carbon, 2005, 43, 2330.

39 T. W. Zerda, W. Xu, H. Yang and M. Grespacher, Rubber Chem. Technol., 1998, 71, 26.

40 (a) W. H. Hess, C. R. Herd, In: J.-B. Donnet, R. C. Bansal and M.-J. Wang, Carbon black, 2nd ed., New York, USA: Marcel Dekker Inc, 1993, 89; (b) F. Tuinsta and J. L. Koenig, J. Chem. Phys., 1970, 53, 1126. 